\title{
Initial Coin Offering (ICO): a systematic review of the literature
}

\author{
Ana Claudia Moxotó \\ University of Coimbra \\ Email:anamoxoto@gmail.com
}

\author{
Paulo Melo \\ University of Coimbra \\ Email pmelo@fe.uc.pt
}

\author{
Elias Soukiazis \\ University of Coimbra \\ Email elias@fe.uc.pt
}

\begin{abstract}
Initial ICO coin offerings have emerged as a new business financing mechanism. ICOs have raised more than \$31.14 billion by 2019, sparking interest in finance studies. Despite ongoing scientific research on the topic, academic knowledge remains limited and fragmented. This study aims to conduct a systematic review of the literature with 30 contributions from journals published until January 2020. Based on an indepth analysis of the publications identified, we describe the landscape of the field of ICOs focusing on two aspects. First, we conducted an analysis of the empirical articles that addressed the success determinants of ICOs. Second, we categorize relevant contributions in five different perspectives: human and social capital, technological characteristics, governance and legal aspects and financial details of the campaign. Thematic analysis was carried out to address dominant themes and subthemes in each perspective.
\end{abstract}

\section{Introduction}

Technology startups are currently attracting the interest of many investors and are already raising large sums of money, which arouses the interest of studies for corporate finance [22], [38], [39]. New ventures need resources to be successful. One of the most critical resources is having access to finance [8], [40], [41]. Agency problems, information asymmetries, the lack of cash flows and guarantees make it difficult for entrepreneurial companies to raise funds [36, p. 18]. There are many barriers encountered in traditional investment mechanisms, which increase costs for entrepreneurs and also increase the risk for financial credit institutions [42], [43]. In this scenario of credit scarcity, token offerings, or ICOs, have emerged as an alternative business financing mechanism.

According to PwC's 6th ICO / STO Report, initial token offerings have already raised by the year 2019 more than 31.14 billion (m.m.) dollars of this total, 4.12 m.m. of dollars were collected in 2019. In 2018, there was a great peak of fundraising in this modality, reaching the value of 19.67 m.m. of dollars. In 2017, 7 m.m. of dollars. The average campaign time also went from 29 days in 2017 to 81 days in 2019, according to the report.

According to the ICOBench website, 5,470 campaigns were completed by November 2019, of which 1,785 were successful and 3,685 failed. Among the sectors that raised the most funds through the sale of tokens, the following stand out (in billions of dollars): Cryptocurrency (\$14.8), Platform (\$ 12.6), Business services (\$ 4.3), Infrastructure (\$ 3.7), Banking (\$ 3.7), among others .The USA, Singapore and Hong Kong are among the main countries in terms of number of campaigns throughout 2018 and 2019, which indicates a strong positioning of these countries in the offer of tokens. In Europe, Switzerland and the United Kingdom lead in number of offers completed in the period, followed by Estonia and Lithuania.

In this context, this theme is emerging as a promising area of research within the broader sphere of entrepreneurship research [36] - [55] - [57]. Since the first publications in 2017, the number of studies on ICO's has increased by approximately 700\% from 2017 to 2019. In 2017, 280 articles on the topic were published on Google Scholar. In the 2017-2018 interval, 848 articles were published on the topic. From 2017 to the end of 2019 there were already more than 2000 publications. In addition, the integration of theories and concepts from areas such as law for example Kaal [102], as well as in the area of computing and engineering [21]. exhibit its inherent interdisciplinary nature as a field of research

Researchers, professionals and policy makers highlight the importance of this new mechanism for financing new ventures [1] - [7] - [11]. The ongoing scientific discussion of ICOS in various academic entrepreneurship journals (for example, Small Business Economics; Journal of Business Venturing; Venture Capital) contributes to the continued legitimation of ICO's as a research sub-field in business finance.

The constant growth and multidisciplinary nature of the field studied makes it difficult to systematize the ICO literature, and a holistic overview of the field is necessary. This study continues as follows: in the next section, we explain the definition of the term ICO. Next, we describe the method applied and also illustrate the 
research and literature review strategy. Then, we present how to measure success in this modality and present the conclusions of systematic literature review. We included a descriptive analysis of the scientific development of funding research in the ICO modality, the synthesized results of the thematic analysis and signaled the possible paths for future research. We conclude by summarizing our main conclusions. Technology startups are currently attracting the interest of many investors and are already raising large sums of money, which arouses the interest of studies for corporate finance [22], [38], [39]. New ventures need resources to be successful. One of the most critical resources is having access to finance [8], [40], [41]. Agency problems, information asymmetries, the lack of cash flows and guarantees make it difficult for entrepreneurial companies to raise funds [36, p. 18]. There are many barriers encountered in traditional investment mechanisms, which increase costs for entrepreneurs and also increase the risk for financial credit institutions [42], [43]. In this scenario of credit scarcity, token offerings, or ICOs, have emerged as an alternative business financing mechanism.

This study continues as follows: in the next section, we explain the definition of the term ICO. Next, we describe the method applied and also illustrate the research and literature review strategy. Then, we present how to measure success in this modality and present the conclusions of systematic literature review. We included a descriptive analysis of the scientific development of funding research in the ICO modality, the synthesized results of the thematic analysis and signaled the possible paths for future research. We conclude by summarizing our main conclusions.

\section{Definition of initial coin offerings (ICOs)}

There are many definitions for an initial coin offering (ICO) in the field of business finance. This financing modality, although still a recent phenomenon [1] - [3] has become an increasingly popular way to increase capital for blockchain technology startups [2], [4], [5].

ICOs are also known as token sales [6], as in this modality new ventures increase capital by selling tokens to a multitude of investors [7]. This fundraising mechanism is similar to that of crowdfunding campaigns in terms of the use of digital platforms and the absence of standard financial intermediaries [8]. However, what really differentiates ICOs from other alternative financing mechanisms is the issuance of cryptographic tokens. Thus, tokens, after being issued, are sold to investors as a way of financing projects [6], [7], [9] - [11].
According to Fisch [7], a token corresponds to a unit of value issued by an enterprise and covers a wide range of applications. These tokens can serve several purposes.

Fisch [7], points out that the classifications of token types, from a theoretical point of view, are not yet unanimous and binding. Some authors, for example, say that tokens can be classified into two groups: cryptocurrency and cryptoassets [12] - [15]. Because they believe that it is more than common among regulators and professionals, Giudici and Adhami [16] adopt the following classification: (1) cryptocurrency or digital currency, which can be subclassified into payment token or stablecoin (if the token can be used as crypto currency) and cryptoassets that are classified as: (2) security token (allows the investor to enjoy profit rights in some cases the right to vote or even to contribute to the project), (3) utility token (allows access to services or exclusive products of the platform. It is possible for the same startup to be able to issue more than one type of token for each project. The choice of the ideal token for each project is related to financing needs, agency problems, as well as platform characteristics [17 ]. Crypto currencies are issued, distributed and controlled by their issuers. However, for traditional money, these functions are performed by a central bank [22], [23]. Instead of a central authority or government, the ICOs that issue the digital currencies are the ones who determine the price of the coins on the network [1 ], [24] - [26]. Some authors claim that ICOs democratize access to finance, reduce transaction costs and offer a decentralized alternative to traditional systems for storing securities [23] - [25], [27], [28].

Many enterprises create their own cryptocurrency by issuing tokens, which are intended to function as an exclusive currency within the enterprise's own ecosystem, they are the utility tokens [7].

ICO is still a very recent phenomenon, despite having its initial launch in 2013, it was highlighted and became popular only in 2017 as an alternative financing mechanism [37].

\section{Methodology}

The ongoing scientific discussion of ICOs in various academic journals on business finance and entrepreneurship, as well as in some on information systems and law, contributes to legitimize the topic in the field of business finance research. In addition, the integration of theories and concepts from areas such as law and information systems indicates the growing importance of ICOs for actions outside the restricted context of research on entrepreneurship and finance.

The aim of this study is to systematically review, categorize and synthesize the existing body of 
knowledge from empirical research to compile a distinct landscape of scientific development.

The literature review process in this article follows common and established guidelines [44], [45]. The IS literature on the subject, which determines the success of ICOs, was considered.

The review process includes several steps based on the three stages (planning and selection, extraction and execution), as demonstrated by Okoli [44] As a first step, we conducted an in-depth literature search on four data sites, including EBSCO, Elsevier, Google Scholar and Web of Science.

Considering the interdisciplinary nature of the subject, we also use Google Scholar in the research, using Publish or Perish software, version 4. As a multidisciplinary database, Google Scholar is not limited to the journals listed in the ISI (International Scientific Index), it includes publications in English and provides greater coverage of unpublished contributions, such as working papers and conference proceedings.

The review is based on databases covering the most important IS journals and conferences. In this first stage, a literature review was carried out to obtain a general understanding of its current state of development of the theme. Based on the combinations of the search terms "initial coin offering", we perform a title, summary and keyword search.

The research was carried out in January 2020, with a time horizon from 1945 to January 2020 and was limited to contributions published in English.

At this stage of execution, thematic analysis results will be categorized into groups. To navigate the complexity, the relevant contributions can be divided into different categories: human and social capital, technological characteristics, governance and legal aspects and financial details of the campaign. Within each of the categories, several sub-sectors emerged. This categorization structure is theoretically supported by studies by Ahlers et al. [46] and Lukkarinen et. Al. [47] applied in crowdfunding studies. For each perspective, we present the synthesis of each theme and the possible opportunities for advancing research on the theme.

\section{Definitions of Success for an ICO.}

\subsection{Signaling Theory for ICOs}

The ICO market still presents many risks, including low investor protection, a limited set of information available and virtually no supervision by public authorities. Unlike established businesses, ICO projects are characterized by strong information asymmetry and opacity [1]. This market is far from being transparent in information. This is due to false declarations, lack of specific technological knowledge and proven fraud, which results in severe information asymmetries [7], [37], [48]. In many studies on ICOs, they use signaling theory [49] to explain the determinants of success for ICOs [7]. According to this theory, the importance of good signage is to reduce risks for investors. ICOs are considered to be high-risk investments with a high potential for fraud. Although these digital assets may present a new and efficient means of carrying out financial transactions, they also increase the risk of fraud and manipulation, because the markets for these assets are less regulated than traditional capital markets [50]. Thus, it is very important to reduce information asymmetries, signaling the quality of the project, the technological and team capacities, in order to obtain successful financing. The corporate finance literature states that potential investors prefer to invest in high quality ventures, because they are more likely to succeed [7], [46]. In addition, these ventures, in general, are in early stages, so it is important to signal the quality of the project and can increase the chances of success, as investors are averse to high risks [7]. Often, these ventures in early stages, do not have a proven track record of a developed product.

\subsection{Measure Success}

Several ways were used to measure success in the context of corporate finance. Among them, the amount of financing raised was used, a measure commonly used in crowdfunding corporate finance studies [8], [46]. ICOs, as an alternative financing modality, exhibit similarities with the classic crowdfunding markets. Therefore, there are similarities in the determinants of financing success in relation to the characteristics of human capital, quality of the business model, project design and social media activity for project dissemination [51]. Also studies related to ICOs show that the amount raised in the campaign can be used as a proxy for success [6], [7], [9], [37], [52].

ICOs can also specify a minimum limit (soft-cap) and a maximum limit (hard-cap) of fundraising as a way to achieve success [1], [28], [53]. After the end of the campaign period, if the minimum limit specified for financing is reached, the tokens will be issued and allocated to buyers. In return, buyers send fiat currencies or cryptocurrencies to issuers. However, if the ventures do not reach the soft-cap during the campaign, the funds will be returned to potential buyers.

Amsden and Schweizer [37] state that the measure of punctual success is given by the total value raised or 
if the "target quantity" is reached. However, they argue that long-term success is ICO's strongest measure of success. It happens when the token is issued and later listed on an exchange platform (secondary token market) and if it is actively traded (it has liquidity).

Based on theories related to IPOs, underpricing is used in some studies as a proxy for success in other types of financing. Underpricing occurs as a result of the large information asymmetry between the ICO issuer and the investor. In this case, the token is measured at a price less than the fair value, which means that the price at which a company issues an asset is below the market value [54]. However, the price of tokens issued in the ICO phase, adjusts to a market price during the listing phase in the secondary market. The underpricing strategy is used to attract more investors in the primary campaign phase. Some studies use underpricing to assess the success of an ICO [1], [11], [54]. Felix et.al [54] affirm that the results show an average level of underpricing of ICOs of $123 \%$ in the USA. Success by the speed of fundraising, which is measured by the total number of days in an ICO campaign[55].

\section{Thematic analysis}

\subsection{Persons}

5.1.1. Team. Team. Previous research shows the importance of a project team as an indicator of the quality of a project and a relevant factor in attracting investors [37], [43], [46], [56]. However, given the peculiarities of ICOs, compared to more traditional financing modalities, the risk of identity fraud is greater. The impact of the team in a given project may be more pronounced in ICOs than in more traditional settings [7]. The quality of the management team is a first-rate indicator for the success of ICO projects [11], [27]. Several studies have examined the association between the success of the ICO and information released about (1) the team in general; (2) team members' reputation and experience; and (3) team size.

5.1.2.Managerial experience. The previous managerial experience of the proponents is a valuable asset for employees [16]. Koch \& Siering [62] claim that creating more projects leads to a learning effect; which means that the founder gains skills on how to better present the project and how to succeed in the financing process and this experience has an effect on the financing decisions of potential investors. Thus, a founder who is dedicated to conducting projects for a considerable time is seen as more reliable and more competent compared to new members who create a project for the first time on the platform.

\subsection{Technological characteristics}

5.2.1. Source code. The source code of an enterprise is the result of programming activities and is also a central component of a technology-based enterprise. The source code of an enterprise also signals its technological capabilities [5] - [7]. The success of the campaign is more likely to occur in ventures where source code is available [37]. Some authors believe that the likelihood of an ICO's success is not affected by the availability of a white paper, but is strongly and positively affected by the presence of the source code of the blockchain project [1]. On the other hand, a negative aspect of publicly disclosing the source code, ICOs allow other ventures to copy the technology and in this way, they may lose their competitive advantage [53], [65]

5.2.2.Token type. The big difference between ICOs and other financing modalities is the possibility of issuing tokens. ICO investors assign higher ratings to utility tokens or security tokens [1], [7], [66]. Empirical evidence reveals that the crypto market has been dominated by utility tokens. Momtaz et.al. [10], states that about $69 \%$ of all token sales can be classified in this category and, in general, utility tokens reflect more than $90 \%$ of the total funds collected. On the other hand, less than $5 \%$ is reflected by security tokens. However, Fisch [7] finds no significant difference between the different types of tokens and the amount raised in the campaign.

5.2.2.Token type. The big difference between ICOs and other financing modalities is the possibility of issuing tokens. ICO investors assign higher ratings to utility tokens or security tokens [1], [7], [66]. Empirical evidence reveals that the crypto market has been dominated by utility tokens.

5.2.3.Ethereum platform. Ethereum was the first platform to popularize and implement "smarts contracts" and "dApps" (decentralized applications), which allow the use of Ethereum's blockchain for various applications. According to Fisch and Momtaz [69], the Ethereum platform (ERC20) serves as the basis for $88.1 \%$ of all ICOs studied. One of the advantages pointed out by the literature regarding the use of the Ethereum platform is the greater interoperability between the parts of the transaction in the Ethereum ecosystem. Thus, the offer of a token based on the Ethereum platform may signal a greater technical 
capacity compared to the other platforms that issue tokens [7], [28]

\subsection{Governance and Legal Aspects}

5.3.1. White paper. it is a document in which an enterprise provides relevant information to the public and is an important component of an ICO campaign [7], [16], [52]. Authors believe that the dissemination of white papers are indispensable for the success of the campaign, together with a high quality source code, as they increase the amount collected [7], [52].There is still a great divergence of opinion on the ideal size of the white paper. While some authors argue that ventures that provide more information, and therefore white papers, may be more attractive to potential investors [70]. Amsden \& Schweizer [37], measure the quality of the white paper by the number of pages in it. However, other authors claim that the length of the white paper does not necessarily indicate quality [65], as some ICOs tend not to systematically follow the information disclosed in the white papers [67].

5.3.2. Social media. Investor comments on social media play an information surveillance role, especially in an unregulated market like ICOs. The importance of social media can be attributed to the reduction of information asymmetries associated with the market. Thus, ventures disclose their information on a social media platform to promote relationships between issuers and investors [6], [65], [71], [72]. Due to the uninterrupted nature of token offers, they depend largely on these social media as channels of direct communication to their dispersed investor base.

However, not all literature agrees with the importance of social media and this issue is not yet a consensus. Chen at.al. [6] highlight that the role of social media, such as the types of platforms, the characteristics of users and the communication channels should be further investigated, both in the ICO issuance phase and also in the value of post-ICO negotiations ( listing phase) [6].

5.3.3. VC support. Although ICOs are a type of financing that is considered to be "democratic", due to the opportunity of access to the general public for investment in new ventures, conventional institutional investors, such as VCs (venture capital), seem to be investing more and more in tokens, especially in the most expensive ICOs. sought by the market. Some existing studies on ICOs model the choice of financing modality between ICOs and venture capital [9], [76]. Chod at. al. [9], says that the ICO modality may be preferable to venture capital financing, although it is desirable to regulate the ICO market to reduce the information asymmetry between entrepreneurs and investors. Lukkarinen et. al. [47], find no evidence that the investment criteria traditionally used by VC investors would be relevant in predicting the success of the crowdfunding campaign.

5.3.4. KYC. Many token offerings impose restrictions on investors, such as whitelists or KYC (Know-YourCustomer) processes. These can reduce the number of potential investors due to the additional cost and increase the time it takes to raise funds from ICO and can influence ICO's performance [77], [78]. On the other hand, investor restrictions ensure that ventures know who invests in their platform and can also help to create long-term relationships between issuers and investors [7].

5.3.5. Intermediate Evaluation (Rating). ICO rating sites play an important role in this market. Broader coverage of the campaign by these reviewers can then lead to a more successful token sale. Thus, ICOs with above-average ratings outperform token sales compared to lower ratings [4], [52], and the likelihood of attracting more VC funding [47], [69] increases. Higher rated ICOs are more likely to obtain resources and tokens are also more liquid and less likely to fail after the completion of the ICO. In general, research points to the importance of evaluating information intermediaries in the functioning of the unregulated cryptography market [53]

5.3.6. Tokens and property rights. Property rights in ICOs are intrinsically related to the characteristics of each type of token. In general, tokens rarely offer property rights to investors, and in fact, most ventures retain full ownership, regardless of the share of tokens offered. Some ventures offer participation in the future revenue of the venture, which allows an entrepreneur to transfer part of the venture's risk to diversified investors, but without diluting their control rights [7], [9]. However, ICOs, in general, tend to offer utility tokens without explicit ownership rights or future cash flows. These tokens do not offer ownership and control rights, therefore, investor legal protection for this type of token is currently almost nonexistent. [76], [79], [80]. Governance rights associated with tokens appear to have an impact on the likelihood of success [16].

5.3.6.Patents. When launching an ICO to be able to finance their ventures, entrepreneurs publicly disclose their ideas and business strategies. Thus, they assume the risk of misappropriation of this information by competitors. Due to this public disclosure of the project, 
it is necessary to protect the company's intellectual capital through patents or trademarks.

5.3.7.Financial systems developed. Huang, Meoli and Vismara [87] analyze the geography of ICOs. According to the authors, ICOs occur more frequently in countries with developed financial systems, public equity markets and advanced digital technologies.

5.3.8.Gender heterogeneity. Howell et. al. [33] researched 387 ICOs about the main founder or CEO and found that $97 \%$ are male. Ibba et.al [88] point out that the number of men is about 5 times greater than the number of women in ICO teams. There is no case of a team composed only of women. The male predominance has already been studied in corporate finance in other types of financing [89] - [92]. There are many gender-related differences in the behavior of investors in companies seeking financing. In addition, investors are more likely to invest in projects where the proportion of male investors is higher. Cumming et al. [92] point out that the ethical basis and risk aversion, makes the gender diversity on the boards of directors can act as a moderator for the frequency of fraud.

5.3.9.Family. In line with the empirical literature on the subject, those with two members of the senior management team with the same family name are identified as family businesses [63], [93]. Astrachan et al., [94] claim that $85 \%$ of all established enterprises start with some level of family support. Parker [95] reports that $31 \%$ of start-up funds come from friends and family. Friends and family tend to contribute at the beginning of the venture's financing cycle [96] and that entrepreneurs give these members greater participation in their business and treat all members equally, regardless of their contribution [97].

5.3.9. Crowdfunding platforms. Huang, Meoli and Vismara [87] claim that countries where there is a greater availability of equity crowdfunding platforms are also more likely to have ICOs. This issue is explained due to the maturity of the use of technological mechanisms to finance entrepreneurial projects already well developed in these countries. They also point out that ICOs are more likely to emerge in countries with developed financial markets and where information and communication technology is more advanced.

5.3.10.Jurisdiction. Adhami, Giudici, \& Martinazzi [1] found that the minority of enterprises discloses in the White paper the regulatory specifications of the jurisdiction where the ICOs will operate. Despite this, there is still a lot of complexity in the regulatory context that follows each ICO. This regulatory complexity is due to the uncertainties of this barely legalized market, as well as the different regulations between different jurisdictions. In this way, the regulatory uncertainty that permeates the ICOs market means that some enterprises are unable to specify the law and jurisdiction applicable to the business model [52], [65].

5.3.11. Restricted areas. Lists of restricted areas, which specify where the venture cannot operate, are used to ensure compliance with international sanctions and avoid litigation in areas considered to be at high risk, this reduces the uncertainty of the venture [37]. These signal that the ICO management knows the regulations of the potential country, reducing the risk of any legal breach or investigation by the authorities of the respective jurisdictions. However, research points out that projects that restrict certain countries (mainly USA and China) decrease the amount raised in the campaign [11], [28]. As these are large investment markets, not operating in these countries could reduce the likelihood of success.

\subsection{Financial details of the campaign}

5.4.1.Disclosure of the application of future revenue. Technology companies can demand big resource commitments to conduct exploratory development projects. However, the desired revenues and profits do not usually happen in the short term. These emerging markets are progressing in unpredictable ways. In this way, information about the quality of technology companies at an early stage should be disseminated to facilitate investment appraisals [103].

5.4.2.Bonus. Token offers that feature bonus structures can encourage investors to increase investment volumes or even to invest in advance and can also attract new investors [1], [109]. Bonus structures reduce the investment risk for investors and can increase the success of the campaign [37]. However, another study indicates that the use of bonuses in the campaign may also signal that the project team is struggling to attract interest from investors and may indicate the lack of quality of the projects. In this regard, further study is considered necessary. different bonus schemes to understand their attractiveness to investors [1].

5.4.3. Campaign time. During the launch phase of the $\mathrm{ICO}$, the project team announces the number of days that the campaign will accept funding, so the campaign time is set in advance. Many studies have already been carried out in other types of crowdfunding, such as crowdfunding, to understand the ideal duration of time 
for campaigns. Mollick [8] and Vismara [59] report that campaigns with a longer duration are less likely to reach their funding goals. This is because a longer campaign can signal a lack of confidence in the project for potential investors. Colombo, Franzoni, \& RossiLamastra [110] claim that when the funding target is reached in just one sixth of the duration it can indicate a positive association with success.

5.4.4. Held tokens. Enterprises that retain a larger fraction of tokens can signal commitment, in addition to aligning the interests of owners and employees (who are generally rewarded with tokens) and investors. The evaluation of the financial details of an ICO, such as the percentage of tokens held by issuers, is a very strong sign of the entrepreneurs' commitment to the success of the business. Thus, higher levels of business confidence in enterprises are positively correlated with the percentage of tokens that they retain [37].

5.4.5. Token provision. Token delivery is defined with the number of tokens issued by an ICO during the campaign. The ventures freely determine the number of tokens that will be issued in the campaign. Companies generally fix the maximum supply of tokens in the smart contract [67]. Fisch (2019) finds a positive relationship between the supply of tokens and the amount raised in the campaign. Studies indicate that it is likely that the greater the number of tokens, the greater the capacity to attract new users and, therefore, the lesser the uncertainty of the enterprise [7], [37]. However, these studies are not yet conclusive.

5.4.6. Legal currency (Fiat). Projects that accept an increase in legal tender, reduce the barriers for investors to enter the new market. A Fiat currency is any legal currency supported by the government. The acceptance of the Fiat currency may presumably signal that the ICO has ties to the traditional banking system, may signal greater reliability of the venture and could potentially increase the number of investors. [11], [37]. However, the use of cryptocurrencies makes transactions more quickly verifiable and involves lower costs than payments using fiat money, which could discourage investors and decrease the chances of a successful venture [10]

5.4.7. Market sentiment. The ICO market is extremely volatile and complex. [67], [72]. ICO teams and investors need to be aware of the speed of change and the technological risks of the market. Software startups in general, and even more startups founded through an ICO, operated under conditions of great uncertainty and the capacity currencies listed during periods with negative investor sentiment generate negative returns in the short term.

\section{Type-style and fonts}

Wherever Times is specified, Times Roman or Times New Roman may be used. If neither is available on your word processor, please use the font closest in appearance to Times. Avoid using bit-mapped fonts if possible. True-Type 1 fonts are preferred.

\section{Conclusions}

The constant growth of publications and the ongoing academic discussion highlight the growing reputation, legitimacy and institutionalization of ICOs as a new field of research in the field of corporate finance. Thus, the aim of our study is to provide a clear picture of current research on funding in this modality and to critically evaluate the existing literature. To navigate the complexity, we present and discuss our results across the categories and perspectives identified. The results of our systematic review and thematic analysis of publications illustrate that ICO research can be categorized into four different perspectives: human and social capital, technological characteristics, governance and legal aspects and financial details of the campaign.

Consequently, our study provides an initial step towards advancing research on ICOs, serving as a scientific knowledge base to guide and encourage future research efforts. As this type of crowdfunding where tokens are issued gains increasing popularity as a viable financing alternative, the analysis of the determinants that predict post-campaign success may be a future research proposal. Studies that evaluate the impact of the covid-19 pandemic on this type of financing would also be interesting. It is known that we still have many challenges for this, due to the innovative character of this modality. Issues related to the correlation between the traditional market and ICOs. However, for the success of this type of crowdfunding in the long term, future studies need to examine which factors determine post-campaign success and whether the signs associated with campaign success are also predictors of the overall success of the venture after a successful campaign. successful. 


\section{References}

[1] S. Adhami et al., "Why do businesses go crypto? An empirical analysis of initial coin offerings," SSRN Electron. J., vol. 100, pp. 1-28, Nov. 2018.

[2] M. Chanson, M. Risius, and F. Wortmann, Initial Coin Offerings (ICOs): An Introduction to the Novel Funding Mechanism Based on Blockchain Technology. aisel.aisnet.org, 2018.

[3] D. Tapscott and A. Tapscott, "How Blockchain Will Change Organizations," MIT Sloan Manag. Rev., vol. 58, no. 2, pp. 10-13, 2017.

[4] A. de Jong, P. Roosenboom, T. van der Kolk, and ..., "What Determines Success in Initial Coin Offerings?," Available SSRN ..., 2018.

[5] J. Conley, "Blockchain and the economics of crypto-tokens and initial coin offerings," no. 2017, 2017.

[6] K. Chen and R. Chen, "Information asymmetry in initial coin offerings (ICOs): Investigating the effects of multiple channel signals," Electron. Commer. Res. Appl., vol. 36, no. January, p. 100858, Jul. 2019.

[7] C. Fisch, "Initial coin offerings (ICOs) to finance new ventures: An exploratory study," J. Bus. Ventur., vol. 34, no. 1, pp. 1-22, Jan. 2019.

[8] E. Mollick, "The dynamics of crowdfunding: An exploratory study,” J. Bus. Ventur., vol. 29, no. 1, pp. 1-16, 2014.

[9] J. Chod and E. Lyandres, "A Theory of ICOs: Diversification, Agency, and Information Asymmetry," SSRN Electron. J., May 2018.

[10] P. P. Momtaz, K. Rennertseder, and H. Schröder, "Token Offerings: A Revolution in Corporate Finance?," Available SSRN ..., 2019.

[11] P. P. Momtaz et al., "Initial Coin Offerings," SSRN Electron. J., no. August, Apr. 2018.

[12] C. Burniske and J. Tatar, "Cryptoassets The Innovative Investor's Guide to Bitcoin and Beyond," 2018.

[13] S. Maxson, S. Davis, and R. Moulton, "UK Cryptoassets Taskforce publishes its final report," J. Invest. ..., 2019.

[14] A. Sterley, "Cryptoassets: Accounting for an Emerging Asset Class," The CPA Journal. search.proquest.com, 2019.

[15] C. Brown, T. Dolan, K. B.- FINTECH, and undefined 2019, "Cryptoassets and Initial Coin Offerings," elgaronline.com.

[16] G. Giudici and S. Adhami, "The Impact of Governance Signals on ICO Fundraising Success," Econ. e Polit. Ind., vol. 46, no. 2, pp. 283-312, Jun. 2019.

[17] L. W. Cong, Y. Li, and N. Wang, "Tokenomics: Cryptocurrency valuation and the roles of tokens," 2018.

[18] Z. Kakushadze, W. Yu, and D. A. Alley, "iCurrency?," 2019.

[19] D. Bullmann, J. Klemm, and A. Pinna, "In search for stability in crypto-assets: are stablecoins the solution?," Occas. Pap. Ser., no. 230, 2019.

[20] R. Copeland, "A Global Stablecoin: Revolutionary Reserve Asset or Reinventing the Wheel?," SSRN Electron. J., 2019.
[21] R. Kulkarni, L. Schintler, N. Koizumi, and R. R. Stough, "Cryptocurrency, Stablecoins and Blockchain: Exploring Digital Money Solutions for Remittances and Inclusive Economies," SSRN Electron. J., 2020.

[22] P. Gomber, J. A. Koch, M. Siering, P. G. J. Koch, and M. Siering, "Digital Finance and FinTech: Current Research and Future Research Directions," J. Bus. Econ., vol. 87, no. 5, pp. 537-580, Jul. 2017.

[23] J. Rohr and A. Wright, "Blockchain-Based Token Sales, Initial Coin Offerings, and the Democratization of Public Capital Markets," Hastings Law J., vol. 70, no. 2, p. 463, 2017.

[24] W. A. Kaal et al., "Initial coin offerings: Emerging practices, risk factors, and red flags," 2018.

[25] Y. Chen, "Blockchain tokens and the potential democratization of entrepreneurship and innovation," Bus. Horiz., vol. 61, no. 4, pp. 567-575, Jul. 2018.

[26] M. Anson, "Initial Coin Offerings: Economic Reality or Virtual Economics?," J. Priv. EQUITY, vol. 21, no. 4, pp. 41-52, 2018.

[27] P. P. Momtaz, "Initial coin offerings, asymmetric information, and loyal ceos," Asymmetric Information, Loyal CEOs (July 12 ..., 2018.

[28] C. Anderson and Y. Tverdov, "Corruption, Political Allegiances, and Attitudes Toward Government in Contemporary Democracies," in SSRN Electronic Journal, 2018, vol. 11, no. 1, pp. 26-32.

[29] L. Ante and I. Fiedler, "Cheap Signals in Security Token Offerings,” SSRN Electron. J., vol. 2019, no. 1, 2019.

[30] J. Biasi and S. Chakravorti, "The future of crypto tokens," in International Finance Review, vol. 20, Emerald Group Publishing Ltd., 2019, pp. 167-187.

[31] S. Gryglewicz, S. Mayer, and E. Morellec, "Financing with Security Tokens *," 2019.

[32] L. Ante and I. Fiedler, "Security Token Offerings on the Blockchain: Capital Market Access for SMEs?," 2019.

[33] S. T. Howell, M. Niessner, and D. Yermack, "Initial Coin O ff erings: Financing Growth with Cryptocurrency Token Sales," 2018.

[34] C. Fisch, C. Masiak, S. Vismara, and J. H. Block, "Motives to invest in initial coin offerings (ICOs)," 2019.

[35] D. Diemers, H. Arslanian, G. McNamara, G. Dobrauz, and ..., "Initial coin offerings: A strategic perspective," Strateg. PwC, 2018.

[36] D. J. Cumming and S. Vismara, "De-segmenting research in entrepreneurial finance," Ventur. Cap., vol. 19, no. 1-2, pp. 17-27, Jan. 2017.

[37] R. Amsden and D. Schweizer, "Are Blockchain Crowdsales the New'Gold Rush'? Success Determinants of Initial Coin Offerings,” SSRN Electron. J., Apr. 2018.

[38] M. Risius and K. Spohrer, "A Blockchain Research Framework,” Bus. Inf. Syst. Eng., vol. 59, no. 6, pp. 385-409, Dec. 2017.

[39] A. Tapscott and D. Tapscott, "How Blockchain Is Changing Finance," pp. 2-6, 2017.

[40] P. Gompers and J. Lerner, "The Venture Capital Revolution,” J. Econ. Perspect., vol. 15, no. 2, pp. 145-168, 2001. 
[41] M. Gorman and W. A. Sahlman, "What do venture capitalists do?," J. Bus. Ventur., vol. 4, no. 4, pp. 231-248, Jul. 1989.

[42] A. Lockett, D. Siegel, M. Wright, and M. D. Ensley, "The creation of spin-off firms at public research institutions: Managerial and policy implications," Res. Policy, vol. 34, no. 7, pp. 981-993, Sep. 2005.

[43] C. Mueller, P. Westhead, and M. Wright, "Formal venture capital acquisition: Can entrepreneurs compensate for the spatial proximity benefits of South East England and 'star' golden-triangle universities?," Environ. Plan. A, vol. 44, no. $2,2012$.

[44] C. Okoli and K. Schabram, "A Guide to Conducting a Systematic Literature Review of Information Systems Research," 2010.

[45] J. Webster and R. T. Watson, "Analyzing the Past to Prepare for the Future: Writing a Literature Review.," MIS Q., vol. 26, no. 2, pp. xiii-xxiii, 2002.

[46] G. K. C. Ahlers, D. Cumming, C. Günther, and D. Schweizer, "Signaling in Equity Crowdfunding," Entrep. Theory Pract., vol. 39, no. 4, pp. 955-980, Jul. 2015.

[47] A. Lukkarinen, J. Teich, H. Wallenius, and J. Wallenius, "Success drivers of online equity crowdfunding campaigns," Decis. Support Syst., vol. 87, no. C, pp. 26-38, Jul. 2016.

[48] D. Liebau and P. Schueffel, "Crypto-Currencies and ICOs: Are They Scams? An Empirical Study," An Empir. Study (January 23, 2019), 2019.

[49] H. E. Leland and D. H. Pyle, "Informational Asymmetries, Financial Structure, and Financial Intermediation,” J. Finance, vol. 32, no. 2, p. 371, May 1977.

[50] J. Clayton, "Statement on Cryptocurrencies and Initial Coin Offerings," world, 2017.

[51] L. Ante, P. G. Sandner, I. Fiedler, and ..., "Determinants and impact of blockchain-based startup financing: The case of initial coin offerings," Crowdinvesting ..., 2017.

[52] S. Samieifar and D. G. Baur, "Read me if you can! An analysis of ICO white papers," Finance. Res. Lett., no. September 2019, p. 101427, 2020.

[53] T. Bourveau, E. T. De George, A. Ellahie, and D. Macciocchi, "Information Intermediaries in the CryptoTokens Market," SSRN Electron. J., 2019.

[54] T. H. Felix and H. von Eije, "Underpricing in the cryptocurrency world: evidence from initial coin offerings," Manag. Finance., vol. 45, no. 4, pp. 563-578, Apr. 2019.

[55] J. Anww, T. Duan, W. Hou, and X. Xu, "Initial Coin Offerings and Entrepreneurial Finance: The Role of Founders' Characteristics," J. Altern. ..., 2017.

[56] J. Sorensen and P. Chang, "Determinants of Successful Entrepreneurship: A Review of the Recent Literature," SSRN Electron. J., Feb. 2006.

[57] J. An, T. Duan, W. Hou, and X. Xu, "Initial Coin Offerings and Entrepreneurial Finance: The Role of Founders' Characteristics," J. Altern. Investments, vol. 21, no. 4, pp. 2640, Mar. 2019.

[58] A. Rossi, S. Vismara, and M. Meoli, "Voting rights delivery in investment-based crowdfunding: a cross-platform analysis," J. Ind. Bus. Econ., vol. 46, no. 2, pp. 251-281, Jun. 2019.
[59] S. Vismara, "Equity retention and social network theory in equity crowdfunding," Small Bus. Econ., vol. 46, no. 4, pp. 579-590, Apr. 2016.

[60] A. Rossi and S. Vismara, "What do crowdfunding platforms do? A comparison between investment-based platforms in Europe," Eurasian Bus. Rev., vol. 8, no. 1, pp. 93-118, Mar. 2018.

[61] P. Belleflamme, N. Omrani, and M. Peitz, "The economics of crowdfunding platforms," Inf. Econ. Policy, vol. 33, pp. 11-28, Dec. 2015.

[62] J.-A. Koch and M. Siering, "Crowdfunding Success Factors: The Characteristics of Successfully Funded Projects on Crowdfunding Platforms," Twenty-Third Eur. Conf. Inf. Syst., no. May 2015, pp. 1-15, Apr. 2015.

[63] D. Cumming, M. Meoli, and S. Vismara, "Investors' choices between cash and voting rights: Evidence from dualclass equity crowdfunding," Res. Policy, vol. 48, no. 8, Oct. 2019.

[64] P. P. Momtaz, "CEO Emotions and Firm Valuation in Initial Coin Offerings : An Artificial Emotional Intelligence Approach," 2019.

[65] M. Ofir and I. Sadeh, "ICO vs IPO: Empirical Findings, Information Asymmetry and the Appropriate Regulatory Framework," SSRN Electron. J., no. Idc, pp. 1-64, 2019.

[66] M. K. Brunnermeier et al., "Initial Coin Offerings: Financing Growth with Cryptocurrency Token Sales," SSRN Electron. J., 2018.

[67] P. P. Momtaz, "Entrepreneurial Finance and Moral Hazard: Evidence from Token Offerings," Available SSRN, 2019.

[68] J. R. Gan, G. Tsoukalas, and S. Netessine, "Inventory, Speculators and Initial Coin Offerings," Whart. Sch. Res. Pap., 2019.

[69] C. Fisch and P. P. Momtaz, "Venture Capital and the Performance of Blockchain Technology-Based Firms: Evidence from Initial Coin Offerings (ICOs)," Available SSRN 3427025, 2019.

[70] C. Feng, N. Li, M. H. F. Wong, and M. Zhang, "Initial Coin Offerings, Blockchain Technology, and White Paper Disclosures,” SSRN Electron. J., 2019.

[71] J. Zhang, "Voluntary information disclosure on social media," Decis. Support Syst., vol. 73, pp. 28-36, 2015. [72] S. Ibba, A. Pinna, M. Lunesu, M. Marchesi, and R. Tonelli, "Initial Coin Offerings and Agile Practices," Futur. Internet, vol. 10, no. 11, p. 103, Nov. 2018.

[73] P. Belleflamme, T. Lambert, and A. Schwienbacher, Individual crowdfunding practices, vol. 15 , no. 4. Taylor \& Francis, 2013, pp. 313-333.

[74] D. J. Cumming, G. Leboeuf, and A. Schwienbacher, "Crowdfunding Models: Keep-it-All vs. All-or-Nothing," SSRN Electron. J., Jun. 2014.

[75] M. Chanson, J. Gjoen, M. Risius, and F. Wortmann, Initial Coin Offerings (ICOs): The role of Social Media for Organizational Legitimacy and Underpricing. 2018.

[76] C. Catalini and J. Gans, "Initial coin offerings and the value of crypto tokens," no. March, Mar. 2018.

[77] P. P. Momtaz, "The pricing and performance of cryptocurrency,” Eur. J. Finance., vol. 0, no. 0, pp. 1-14, 2019. 
[78] D. Blaseg, "Dynamics of Voluntary Disclosure in the Unregulated Market for Initial Coin Offerings," SSRN Electron. J., 2018.

[79] S. N. Howell and M. Niessner, "M., and Yermack, D.(2018). Initial Coin Offerings: Financing Growth with Cryptocurrency Token Sales,” NBER Work. Pap., 2018.

[80] W. Kaal and M. Dell'Erba, "Initial Coin Offerings: Emerging Practices," Risk Factors, Red Flags, 2017.

[81] D. Frydrych, A. J. Bock, T. Kinder, and B. Koeck, "Exploring entrepreneurial legitimacy in reward-based crowdfunding," Venture Capital, vol. 16, no. 3. Taylor \& Francis, pp. 247-269, 2014.

[82] S. Vismara, "Information cascades among investors in equity crowdfunding," Entrep. Theory Pract., vol. 42, no. 3, pp. 467-497, Jan. 2018.

[83] A. Ralchev and P. Roosenboom, "Forecasting Success in Equity Crowdfunding," SSRN Electron. J., 2018.

[84] A. Signori and S. Vismara, "Does success bring success? The post-offering lives of equity-crowdfunded firms,” J. Corp. Finance., vol. 50, pp. 575-591, Jun. 2018.

[85] A. Ralcheva and P. Roosenboom, "On the Road to Success in Equity Crowdfunding," SSRN Electron. J., 2016.

[86] A. Signori and S. Vismara, "Returns on Investments in Equity Crowdfunding," SSRN Electron. J., pp. 1-43, 2016.

[87] W. Huang, M. Meoli, and S. Vismara, "The geography of initial coin offerings," Small Bus. Econ., pp. 126, Feb. 2019.

[88] S. Ibba, A. Pinna, G. Baralla, and M. Marchesi, "ICOs overview: Should investors choose an ICO developed with the lean startup methodology?," International Conference on Agile .... Springer, 2018.

[89] E. Piva and C. Rossi-Lamastra, "Human capital signals and entrepreneurs' success in equity crowdfunding," Small Bus. Econ., vol. 51, no. 3, pp. 667-686, 2018.

[90] A. Mohammadi and K. Shafi, "Gender differences in the contribution patterns of equity-crowdfunding investors," Small Bus. Econ., vol. 50, no. 2, pp. 275-287, Feb. 2018.

[91] S. Vismara, D. Benaroio, and F. Carne, "Gender in entrepreneurial finance : matching investors and entrepreneurs in equity crowdfunding," Ssrn, 2016.

[92] D. Cumming, T. Y. Leung, and O. Rui, "Gender diversity and securities fraud,” Acad. Manag. J., vol. 58, no. 5, pp. 1572-1593, 2015.

[93] J. Kotlar, A. Signori, A. De Massis, and S. Vismara, "Financial wealth, socioemotional wealth, and IPO underpricing in family firms: A two-stage gamble model," Acad. Manag. J., vol. 61, no. 3, pp. 1073-1099, 2018.

[94] J. H. Astrachan and M. C. Shanker, "Family Businesses' Contribution to the U.S. Economy: A Closer Look," Fam. Bus. Rev., vol. 16, no. 3, pp. 211-219, 2003.

[95] S. C. Parker and C. M. Van Praag, "The entrepreneur's mode of entry: Business takeover or new venture start?," J. Bus. Ventur., vol. 27, no. 1, pp. 31-46, Jan. 2012.

[96] A. Agrawal, C. Catalini, and A. Goldfarb, "Are Syndicates the Killer App of Equity Crowdfunding?," SSRN Electron. J., Feb. 2015.
[97] I. Borst, C. Moser, and J. Ferguson, "From friendfunding to crowdfunding: Relevance of relationships, social media, and platform activities to crowdfunding performance," New Media Soc., vol. 20, no. 4, pp. 1396-1414, 2018.

[98] T. Zellweger and P. Sieger, "Entrepreneurial orientation in long-lived family firms," Small Bus. Econ., vol. 38, no. 1, pp. 67-84, Jan. 2012.

[99] Y. Ahn and D. Kim, "Sentiment disagreement and bitcoin price fluctuations: a psycholinguistic approach," Appl. Econ. Lett., vol. 27, no. 5, pp. 412-416, Mar. 2020.

[100] A. Ljungqvist, V. Nanda, and R. Singh, "Hot Markets, Investor Sentiment, and IPO Pricing," Source J. Bus., vol. 79, no. 4, pp. 1667-1702, 2006.

[101] C. J. Campbell, Y. Du, S. G. Rhee, and N. Tang, "Finance Publication Market Sentiment, IPO Underpricing, and Valuation," 2008.

[102] W. A. Kaal, "Initial Coin Offerings: The Top 25 Jurisdictions and their Comparative Regulatory Responses," CodeX Stanford J. Blockchain Law Policy, vol. 1, pp. 0-22, 2018.

[103] S. Shane, T. Stuart, S. Shane, and T. Stuart, "Organizational Endowments and the Performance of University Start-ups,” no. June 2017, 2002.

[104] G. K. Ahlers et al., "Signaling in Equity Crowdfunding Entrepreneurship Entrepreneurship," Eur. Finance. Manag. Assoc. (Reading Univ., vol. 2014, 2013.

[105] E. R. Mollick and V. Kuppuswamy, "After the Campaign: Outcomes of Crowdfunding," SSRN Electron. J., Jan. 2014.

[106] W. A. Kaal, Financial Technology and Hedge Funds. papers.ssrn.com, 2019.

[107] H. E. Benedetti and L. Kostovetsky, "Digital Tulips? Returns to Investors in Initial Coin Offerings," Returns to Investors Initial Coin Offer. (May 20, 2018), no. May 2018, 2018.

[108] S. T. Howell, "Applications in Entrepreneurial Finance." w4.stern.nyu.edu, 2018.

[109] F. Hartmann, X. Wang, and M. I. Lunesu, Evaluation of Initial Cryptoasset Offerings- The State of the Practice. IEEE, 2018, pp. 33-39.

[110] M. G. Colombo, C. Franzoni, and C. RossiLamastra, "Internal Social Capital and the Attraction of Early Contributions in Crowdfunding," Entrep. Theory Pract., vol. 39, no. 1, pp. 75-100, Jan. 2015. 